\title{
INTEGRALS OF RATIOS OF FOX-WRIGHT AND INCOMPLETE FOX-WRIGHT FUNCTIONS WITH APPLICATIONS
}

\author{
Khaled Mehrez And Tibor K. PogÁny*
}

\begin{abstract}
The main focus of the present paper is to establish definite integral formulae for ratios of the Fox-Wright functions. As consequences of the master formula, some novel integral formulae are derived for ratios of other special functions which are associated to Fox-Wright $\Psi$ function, like generalized hypergeometric function, modified Bessel function of the first kind and Mittag-Leffler type functions of two and three parameters. Moreover, closed integral form expressions are obtained for a family of Mathieu-type series and for the associated alternating versions whose terms contain the incomplete Fox-Wright function. As applications, functional bounding inequalities are established for the aforementioned series.
\end{abstract}

Mathematics subject classification (2020): 26D15, 33C20, 33C70, 33E12, 40C10.

Keywords and phrases: Complete and incomplete Fox-Wright function, generalized hypergeometric function, Mittag-Leffler functions of two and three parameters, Mathieu-type series, bilateral functional inequalities.

\section{REFERENCES}

[1] Á. BARICZ, Turán type inequalities for modified Bessel functions, Bull. Aust. Math. Soc., 82 (2010), 254-264.

[2] Á. Baricz, D. Jankov Maširević And T. K. PogÁny, Series of Bessel and Kummer-Type Functions, Lecture Notes in Mathematics, 2207. Springer, Cham, 2017.

[3] E. CAHEn, Sur la fonction $\zeta(s)$ de Riemann et sur des fontions analogues, Ann. Sci. l'École Norm. Sup. Ser. Math., 11 (1894), 75-164.

[4] A. Erdélyi, W. Magnus, F. Oberhettinger and F. Tricomi, Tables of Integral Transforms I, McGraw-Hill Book Company, New York, Toronto and London, 1954.

[5] C. Fox, The asymptotic expansion of generalized hypergeometric functions, Proc. Lond. Math. Soc., S2-27 (1928), No. 1, 389-400.

[6] I. S. Gradshteyn And I. M. Ryzhik, Tables of Integrals, Series, and Products, (Corrected and Enlarged Edition prepared by A. Jeffrey and D. Zwillinger), sixth ed., Academic Press, New York, 2000.

[7] E. K. IfANTIS AND P. D. SiAfariKas, Inequalities involving Bessel and modified Bessel functions, J. Math. Anal. Appl., 147 (1990), No. 1, 214-227.

[8] C. M. Joshi And S. K. Bissu, Some inequalities of Bessel and modified Bessel functions, J. Aust. Math. Soc. Ser. A 50 (1991), 333-342.

[9] A. A. Kilbas, Fractional calculus of the generalized Wright function, Fract. Calc. Appl. Anal., 8 (2005), 114-126.

[10] YU. LuChKo AND R. GoRenflo, Scale-invariant solutions of a partial differential equation of fractional order, Fract. Calc. Appl. Anal., 1 (1998), 63-78.

[11] Y. L. LUKE, Inequalities for generalized hypergeometric functions, J. Approx. Theory, 5 (1972), $41-$ 65.

[12] F. Mainardi And G. Pagnini, The role of the Fox-Wright functions in fractional sub-diffusion of distributed order, J. Comput. Appl. Math., 207, 2 (2007), 245-257.

[13] K. MehreZ, New integral representations for the Fox-Wright functions and its applications, J. Math. Anal. Appl., 468 (2018), 650-673. 
[14] K. MenreZ, New properties for several classes of functions related to the Fox-Wright functions, J. Comput. Appl. Math. 362, (2019), 161-171.

[15] K. Menrez, Some geometric properties of a class of functions related to the Fox-Wright functions, Banach J. Math. Anal. 14, (2020), 1222-1240.

[16] K. MehreZ, New integral representations for the Fox-Wright functions and its applications II, J. Contemp. Math. Anal., 56 (2021), No. 1, 37-45.

[17] K. MehreZ And S. M. Sitnik, Functional inequalities for the Fox-Wright functions, Ramanujan J., 50 (2019), No. 2, 263-287.

[18] A. R. MiLler, Solutions of Fermat's last equation in terms of Wright function, Fibonacci Quart., 29 (1991), 52-56.

[19] A. R. Miller, On the Mellin transform of a product of two Fox-Wright psi functions, J. Phys. A: Math. Gen., 35 (2002), 2275-2281.

[20] A. R. Miller ANd I. S. Moskowitz, Reduction of a class of Fox-Wright Psi functions for certain rational parameters, Comput. Math. Appl., 30 (1995), 73-82.

[21] E. Neuman, Inequalities and bounds for the incomplete Gamma function, Results Math., 63 (2013), $1209-1213$.

[22] T. K. PogÁNy, Integral expressions of Mathieu-type series whose terms contain Fox's $H$-function, Appl. Math. Lett., 20 (2007), 764-769.

[23] T. K. Pogány and R. K. Parmar, On p-extended Mathieu series, Rad Hrvat. Akad. Znan. Umjet. Mat. Znan., 22 (2018), 107-117.

[24] T. K. Pogány And Ž. Tomovski, On Mathieu-type series whose terms contain generalized hypergeometric function ${ }_{p} F_{q}$ and Meijer G-function, Math. Comput. Modell., 47 (2008), No. 9-10, 952-969.

[25] T. K. Pogány and Ž. Tomovski, Probability distribution built by Prabhakar function. Related Turán and Laguerre inequalities, Integral Transforms Spec. Funct., 27 (2016), No. 10, 783-793.

[26] T. K. Pogány And H. M. SRIVAstaVA, Some Mathieu-type series associated with the Fox-Wright function, Comp. Math. Appl., 57 (2009), 127-140.

[27] T. R. PrabhakAR, A singular integral equation with a generalized Mittag-Leffler function in the kernel, Yokohama Math. J., 19 (1971), 7-15.

[28] H. M. Srivastava, R. K. Saxena And R. K. Parmar, Some families of the incomplete $H$ functions and the incomplete $\bar{H}$-functions and associated integral transforms and operators of fractional calculus with applications, Russian J. Math. Phys., 25 (2018), No. 1, 116-138.

[29] H. M. SRIVASTAVA AND Ž.TOMOVSKI, Fractional calculus with an integral operator containing a generalized Mittag-Leffler function in the kernel, Appl. Math. Comput., 211 (2009), No. 1, 198-210.

[30] B. Stanković, On the function of E. M. Wright, Publ. Inst. Math. (Beograd) (N. S.), 10 (24) (1970), $113-124$.

[31] G. N. Watson, A Treatise on the Theory of Bessel Functions, Cambridge University Press, Cambridge, 1922.

[32] A. Wiman, Über den Fundamentalsatz in der Theorie der Funktionen $E_{a}(x)$, Acta Math., 29 (1905), 191-201.

[33] E. M. WRIGHT, The asymptotic expansion of the generalized hypergeometric function, J. London Math. Soc., 10 (1935), 287-293.

[34] E. M. WRIGHT, The asymptotic expansion of the generalized hypergeometric function, Proc. Lond. Math. Soc. (Ser. 2), 46 (1940), 389-408.

[35] E. M. WRIGHT, The generalized Bessel function of order greater than one, Quart. J. Math. Oxford Ser., 11 (1940), 36-48. 